\title{
Chapter \#17
}

\section{WORK-RELATED STRESS, PERSONAL RESOURCES AND MENTAL HEALTH IN HIGH-RISK PROFESSIONS}

\author{
Martina Chylova ${ }^{1}$, Jana Nezkusilova ${ }^{2}$, \& Monika Seilerova ${ }^{3}$ \\ ${ }^{1} 1$ st Department of Psychiatry, Faculty of Medicine, P. J. Safarik University, Kosice, Slovakia \\ ${ }^{2}$ Department of Psychology, Faculty of Arts, P. J. Safarik University, Kosice, Slovakia \\ ${ }^{3}$ Department of Labour Law and Social Security Law, Faculty of Law, P. J. Safarik University, \\ Kosice, Slovakia
}

\begin{abstract}
The importance of work-related stress and its consequences for mental health is underlined by the increasing prevalence of absence from work due to stress-related illnesses. The aim of this study was to explore how work-related stress and personal resources associate with the perceived anxiety and depression in high-risk professions. The study sample comprised a total of 276 police officers, prison guards, customs officers and physicians $(72.1 \%$ men, an average age of 36.6) who filled out questionnaires concerning sociodemographic variables (age, gender, working time), work-related stress (occupational roles, personal resources), anxiety and depression. The multiple regression analysis was used to analyze data. A model consisting of gender, occupational roles and personal resources explained $39.5 \%$ of the variance in anxiety, and $48.7 \%$ of the variance in depression in the total sample. Gender $(\beta=.22, p \leq .001)$, recreation $(\beta=-.26, p \leq .001)$, social support $(\beta=-.17, p \leq .01)$, and rational/cognitive coping $(\beta=-.17, \mathrm{p} \leq .01)$ were significant predictors of anxiety. Gender $(\beta=.26$, $\mathrm{p} \leq .001)$, insufficiency $(\beta=.11, \mathrm{p} \leq .05)$, ambiguity $(\beta=.13, \mathrm{p} \leq .05)$, recreation $(\beta=-.19, \mathrm{p} \leq .001)$, social support $(\beta=-.19, \mathrm{p} \leq .001)$, and rational/cognitive coping $(\beta=-.24, \mathrm{p} \leq .001)$ were significant predictors of depression. Higher levels of recreation, social support and rational/cognitive coping in the work of high-risk employees are important in diminishing the perceived anxiety and depression, and potentially protecting against work-related stress.
\end{abstract}

Keywords: mental health, work-related stress, anxiety, depression, personal resources, high-risk professions.

\section{INTRODUCTION}

Work has been identified as a significant predictor of mental health problems. In some high-income countries, nearly $40 \%$ of disabilities are caused by the occurrence of mental disorders. The significance of work-related stress and its consequences for mental health is underlined by the increasing prevalence of absence from work due to stress-related illnesses. They belong to the leading causes of disability in Slovakia. Research in the field of work-related stress is still insufficient in Slovakia, although occupational physicians and employers estimate an increasing trend in disability due to mental disorders (Baumann, Muijen, \& Gaebel, 2010; NCZI, 2018).

Work-related stress can lead to many psychological problems, even psychiatric illnesses. When an illness is clearly diagnosed and physical in nature, supervisors and co-workers tend to be much more tolerant of employee absenteeism. In contrast to physical illnesses, the absence for unclear or psychiatric reasons can be especially difficult for employers to understand and accept (Pflanz \& Heidel, 2003). 
Responders included in this study worked in the emergency services in the government and health care. They belong to high risk professions due to their job-related risks that may deteriorate their physical and mental health. They have a dynamic work environment with various psycho-social work stressors. The stressors responsible for poor mental health in customs officers, prison guards or policemen include long hours at work and overtime, conflicting demands, poor social support, badly-designed organizational structure, employee reward system, working with dangerous clients. Furthermore, many physicians are notoriously reluctant to seek help. There is an increased level of psychological morbidity among high-risk employees, such as anxiety, depression, substance abuse or personal problems. When employees with such the symptoms begin to perform poorly, supervisors must look beyond job skills of their deteriorating performance.

The risk professions have long recognized the critical role human factors play in accidents. The distractibility and poor judgment that cause human errors have multiple causes, including unresolved psychiatric illnesses and personal problems (Pflanz \& Heidel, 2003; Schneider \& Weigl, 2018).

Psycho-social work factors may negatively affect the mental health of employees. Employees who worry about the job loss, experience conflicts with co-workers or supervisors, are involved in unchallenging work, or face excessive work demands are bound to experience more absenteeism, less productivity, and decreased job satisfaction. The critical role the work climate plays in the health of employees and the potential contribution of negative work environments contribute to absenteeism and accidents (Pflanz \& Heidel, 2003).

Work-related stress may trigger the onset of anxious disorders or depression (Madsen et al., 2017). Anxiety and depression have become extremely common mental disorders, and are manifested in a varying intensity. The anxiety disorders include panic disorder, generalized anxiety disorder, adjustment disorder with anxious mood, phobic disorder, obsessive-compulsive disorder, and post-traumatic stress disorder (APA, 2018). Generally, anxious employees consider day-to-day events to be threatening, although they are not necessarily serious. During intense fear or discomfort many physical symptoms can develop. This may lead to the avoidance of job tasks instead of utilising effective skills to deal with job tasks. Certain events at the workplace may trigger anxiety. These include job transfers, promotion or demotion, employment of new workers, or lay-offs (Stein \& Hollander, 2003; Maran, Varetto, Zedda, \& Ieraci, 2015).

The employees feeling depression may express emotional, motivational, physiological and cognitive symptoms. Some of them may experience suicidal thoughts or actions (Bennett, 2011). Employees with psychiatric illnesses and other psycho-social problems exhibit a variety of symptoms, including irritability, anger, inattention, apathy, loss of motivation, disinterest, and fatigue. It is not surprising that employees with these symptoms have problems with absenteeism, accidents, interpersonal conflicts, poor job performance, and job dissatisfaction (Pflanz \& Heidel, 2003).

Mental disorders account for $11 \%$ of all medical plan costs, and depression accounts for $52 \%$ of all medical claims for mental disorders. Upon return from disability absence due to depression, $26 \%$ of workers experience another episode of disability due to depression in the following 12 months. The disability relapse rate is significantly greater than the relapse rates for high blood pressure, low back pain, and heart disease. Depression is associated with both longer and more frequent absences from work. Psycho-social problems interfere with day-to day work tasks of risk profession employees, impairing their attention span, motivation, energy, and ability to relate to co-workers and clients or patients (Pflanz \& Heidel, 2003). 
Personal resources, ranking among coping resources, contribute to occupational adjustment. Recreation, self-care, social support and/or rational/cognitive coping resources may play an important role as protective factors in the increase of psychological symptoms. Recreation is one of the most important personal resources of risk profession employees. They may engage in a variety of activities they find relaxing and satisfying. They may do things they enjoy doing the most in their spare time. High levels in self-care domains mean that employees regularly exercise, sleep well, are careful about their diet, practice relaxation techniques, and avoid harmful substances, such as alcohol, drugs, tobacco. Social support reflects that there is at least one person they can count on, one who values or loves them. They may report having a sympathetic person with whom they may talk about work problems. They also may report feeling close to another individual. Rational/cognitive coping resources of employees mean a systematic approach to solving problems, through the consequences of their decisions as well as the ability to identify important elements of problems encountered. They may report being able to set and follow priorities, and having techniques to avoid being distracted. They also may be able to reexamine and reorganize their work schedule. They put their jobs out of their minds when they go home, and feel that there are other jobs besides their present one that they can do (Osipow, 2010; Lovaš, Raczová, Hricová, Mesárošová, \& Kováčová Holevová, 2014).

The current research points out a protective factor in performing recreational activities when recovering from work overload, mainly in high-risk professions. High-risk professionals identified self-care strategies that support their well-being at both institutional and individual levels. The inclusion of self-care and recreational activities exists in the social policy systems of some organizations as regards the mental health care of employees (Kilfedder, 2010, in Baumann et al., 2010; Schwartz et al., 2019; Krick $\&$ Felfe, 2020). The concept of social support as a protective factor in the stress-health theory has been extensively described in the previous publications. They consider the impact of the perceived social integration and social support as a key in the study of stress and health. Extensive research was carried out around the world in the 1980s on various diseases, including depression. In relation to depression, social support has a protective effect as it was revealed in the studies of prison officers, physicians, or police officers (Cohen \& Wills, 1985; Goldberg et al., 1996; Sherwood et al., 2019; Chan \& Andersen, 2020; Sun et al., 2020). Stress is viewed as a transactional process that both influences and is influenced by cognitive appraisal, coping strategies, and stress outcomes. The specific stress management interventions typically entail the positive self-talk, deep breathing, anchoring, cognitive rehearsal and desensitization, progressive muscle relaxation, meditation, imagery and biofeedback, goal setting, stress debriefing, time management, financial planning, visual-motor behavior rehearsal, critical incident stress management, physical fitness, biofeedback, social support, eye movement desensitization and reprocessing (Patterson, Chung, \& Swan, 2012). Cognitive strategies result from the cognitive-behavioral therapy, and their effect on anxiety and depression has been demonstrated in a variety of studies. The effects of stress management interventions on stress outcomes were studied also in police officers or in emergency medical personnel (Sarason, Johnson, Berberich, \& Siegel, 1979; McCammon, Durham, Allison, \& Williamson, 1988; De Vente, Kamphuis, Emmelkamp, \& Blonk, 2008; Hofmann, Asnaani, Vonk, Sawyer, \& Fang, 2012; Patterson et al., 2012). 


\section{OBJECTIVES}

The main objective of this cross-sectional study was to find out how work-related stress and personal resources explain the perceived anxiety and depression in high-risk professions. It was expected that variables of work-related stress explain higher rates of anxiety and depression, while higher levels of personal resources explain less anxiety and depression in the studied sample. The dependent variables were anxiety, depression, while the independent variables were gender, occupational roles and personal resources.

\section{METHODS}

\subsection{Sample and procedures}

The study sample comprised a total of 276 first responders from Slovakia including police officers $(n=69)$, customs officers of the Financial Administration of the Slovak Republic $(n=65)$, prison guards of the Prison and Court Guard Service of the Slovak Republic ( $n=77)$, and physicians working in state hospitals $(n=65)$.

The responders were recruited in various cities of Slovakia after the consent of their head of departments. They were presented the possibility of participating in a mental health survey on a voluntary basis. The survey was usually conducted at the beginning of their work shifts. Firstly, a written informed-consent form was presented, then questionnaires to be filled out on a voluntary and anonymous basis were explained in a group of employees by a psychologist. Each responder provided a signed informed-consent form before participating in this study. The data were collected from December 2018 to April 2019.

The Ethics Committee of the Faculty of Medicine, University of P. J. Śafárik in Košice, Slovakia, approved the study on April, 30 3018.

\subsection{Measures}

The study was conducted by questionnaire concerning socio-demographic variables, a self-reported questionnaire on work-related stress, and two clinical scales. Firstly, responders filled out the questionnaire concerning socio-demographic variables including age, gender, marital status, education level, employment status and working time.

Work-related stress was measured by the Occupational Stress Inventory Revised (OSI-R), particularly by the questionnaires Occupational Role (ORQ, 60 items) and Personal Resources (PRQ, 40 items). The Personal Strain Questionnaire (PSQ) was not taken into account when assessing stress characteristics due to high collinearity with clinical scales used in the study. Responders answer at the 5-degree scale (from Never to Most). The raw score in each dimension has to be converted to a T-score.

The ORQ measures six dimensions: Role Overload (high scorers may describe their work load as increasing, unreasonable, and unsupported; themselves as not feeling well-trained or competent for the job in hand, needing more help, and/or working under tight deadlines); Role Insufficiency (high scorers report a poor fit between their skills and the job they are performing, boredom and/or underutilization); Role Ambiguity (high scorers report an unclear sense of what they are expected to do, how they should be spending their time, and how they will be evaluated); Role Boundary (high scorers may report feeling caught up in between conflicting supervisory demands and factions, not feeling proud of what they do, or not having a stake in the enterprise); Responsibility (high score indicates high levels of responsibility for the activities and work performance of subordinates, having poor relationships with people at work or feeling pressure from 
working with angry or difficult employees or the public); Physical Environment (high score means being exposed to high levels of noise, moisture, dust, heat, cold, light, poisonous substances, having an erratic work schedule or feeling personally isolated). For the ORQ, high scores suggest significant levels of occupational stress. T-scores at or above 70 indicate a strong probability of maladaptive stress. Scores in the range of 60-69 suggest mild levels of maladaptive stress. Scores in the range of 40-59 should be interpreted as being within the normal range. Scores below 40 indicate a relative absence of work-related stress (Osipow, 2010).

The PRQ reports on four dimensions: Recreation (e.g. finding relaxing activities); Self-Care (maintaining healthy behaviour, such as an appropriate diet, sufficient time to sleep, avoiding harmful substances); Social Support (feeling close to another individual, having someone to talk about work problems, spending spare time with someone); Rational/Cognitive Coping (means solving problems adequatly, being able to set and follow priorities, and having techniques to avoid being distracted). Concerning the PRQ scales, high scores indicate highly developed coping resources. T-scores below 30 indicate a significant lack of coping resources. Scores in the range of 30-39 suggest mild deficits in coping skills. T-scores in the range of 40-49 indicate average coping skills, whereas higher scores indicate increasingly strong coping skills (Osipow, 2010).

Anxiety was identified by the State Trait Anxiety Inventory (STAI X-1, 20 items). Responders respond on a 4-point scale. This clinical scale describes the current state of anxiety (feelings of tension, nervousness right now). The cutoff score is 50, higher values are considered to be an increased level of anxiety (Müllner, Ruisel, \& Farkaš, 1980).

The Zung Depression Scale (SDS) is one of the world's most widely used clinical scales that measures current characteristics of depression. It contains 20 items. The responders should indicate the degree on a 4-point scale that best corresponds to their status they had been feeling in the last two weeks. The total score is converted into the SDS index, which expresses the current level of depressive symptoms. The SDS more than 70 points means severe depression (Zung, 1991).

\subsection{Statistical analysis}

Firstly, the socio-demographic variables (age, gender, working time), work-related stress (role overload, role insufficiency, role ambiguity, role boundary, responsibility, physical environment), personal resources (recreation, self-care, social support, rational/cognitive coping), and clinical scales (anxiety, depression) were studied. Pearson's correlations, according to the normal distribution of data, were used for testing the associations between the examined variables.

Then, a hierarchical multiple regression analysis, the stepwise method, was performed to determine predictors of anxiety and depression in this study. In the first step, hierarchical multiple regression analyses with independent variables (gender) were applied in relation to anxiety, and depression separately. In the second step, occupational roles and, in the third step, personal resources were added to the both models, and hierarchical multiple regression analyses were calculated again.

The statistical software IBM SPSS Statistics v.23 was used to analyze the data.

\section{RESULTS}

In general, the responders $(n=276)$ were of middle age $(36.6 \pm 9.0$ years $)$, ranging from 18 to 77 years of age. The sample comprised more men than women ( $72.1 \%$ males). $51.4 \%$ 
of them worked in shifts, $75.7 \%$ worked at night, $62.3 \%$ worked overtime, and $48.2 \%$ worked in the emergency services.

Mean T-scores were similar in the occupational roles ORQ: 47 (role overload), 54 (role insufficiency), 50 (role ambiguity), 53 (role boundary), 46 (responsibility), and 43 (physical environment) in the total sample. The mean T-scores in the personal resources were: 56 (recreation), 49 (self-care), 51 (social support), 52 (rational/cognitive coping) in the total sample. The mean values for anxiety and depression in the total sample were $37.4 \pm 9.8$, and $35.3 \pm 8.3$ (SDS, respectively).

The average value of anxiety was $37.4 \pm 9.8$, and SDS was $44( \pm 8.3)$.

Two models comprised gender, occupational roles ORQ, and personal resources PRQ. The variances in anxiety and depression explained significantly by independent variables can be found in Figure 1.

Figure 1.

Explained variance of anxiety and depression in the total sample.

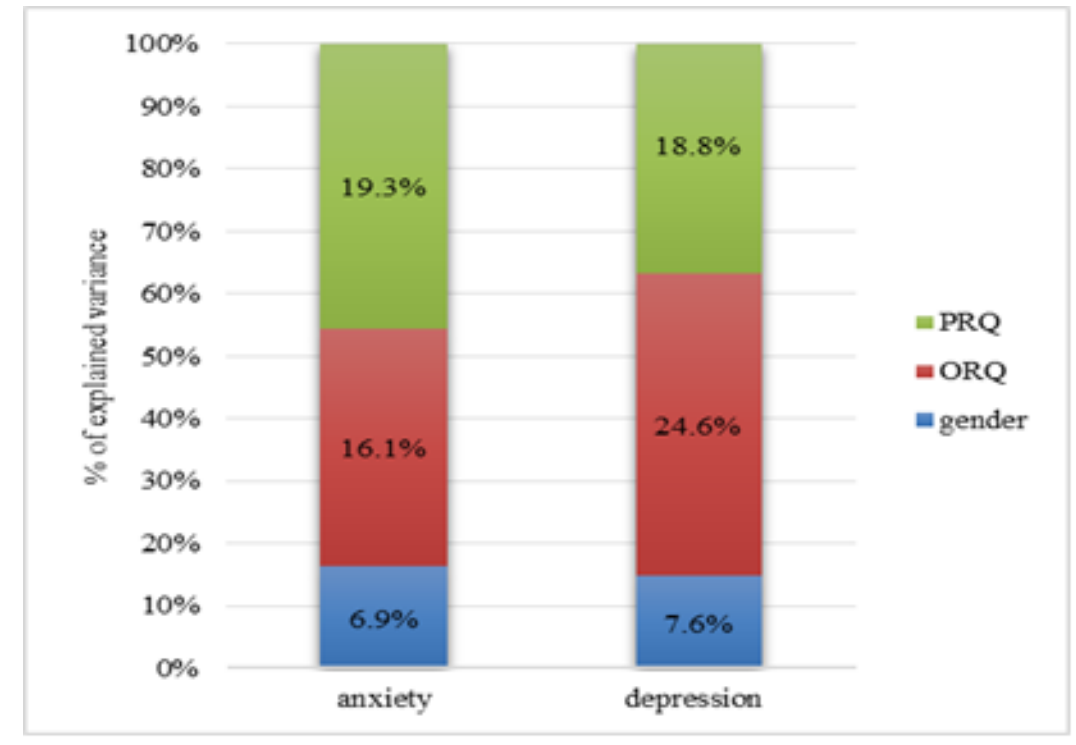

Notes: ORQ=Occupational Role Questionnaire (role overload, role insufficiency, role ambiguity, role boundary, responsibility, physical environment); PRQ=Personal Resources Questionnaire (recreation, self-care, social support, rational/cognitive coping)

Significant predictors of anxiety included female gender $(\beta=.22, p \leq .001)$, lower levels of recreation $(\beta=-.26, p \leq .001)$, of social support $(\beta=-.17, p \leq .01)$, and of rational/cognitive coping $(\beta=-.17, \mathrm{p} \leq .01)$. $\mathrm{R}^{2}$ was reported by $42.3 \%$ in the final model, explaining variance of anxiety (Figure 2).

Significant predictors of depression consisted of female gender $(\beta=.26, \mathrm{p} \leq .001)$, higher level of role insufficiency $(\beta=.11, \mathrm{p} \leq .05)$, of role ambiguity $(\beta=.13, \mathrm{p} \leq .05)$, and lower levels of recreation $(\beta=-.19, \mathrm{p} \leq .001)$, of social support $(\beta=-.19, \mathrm{p} \leq .001)$ and of rational/cognitive coping $(\beta=-.24, p \leq .001) . R^{2}$ was $48.7 \%$ in the final model, explaining variance of depression (Figure 3). 
Work-Related Stress, Personal Resources and Mental Health in High-Risk Professions

Figure 2.

Multiple regression analysis: gender, occupational roles and personal resources on anxiety.

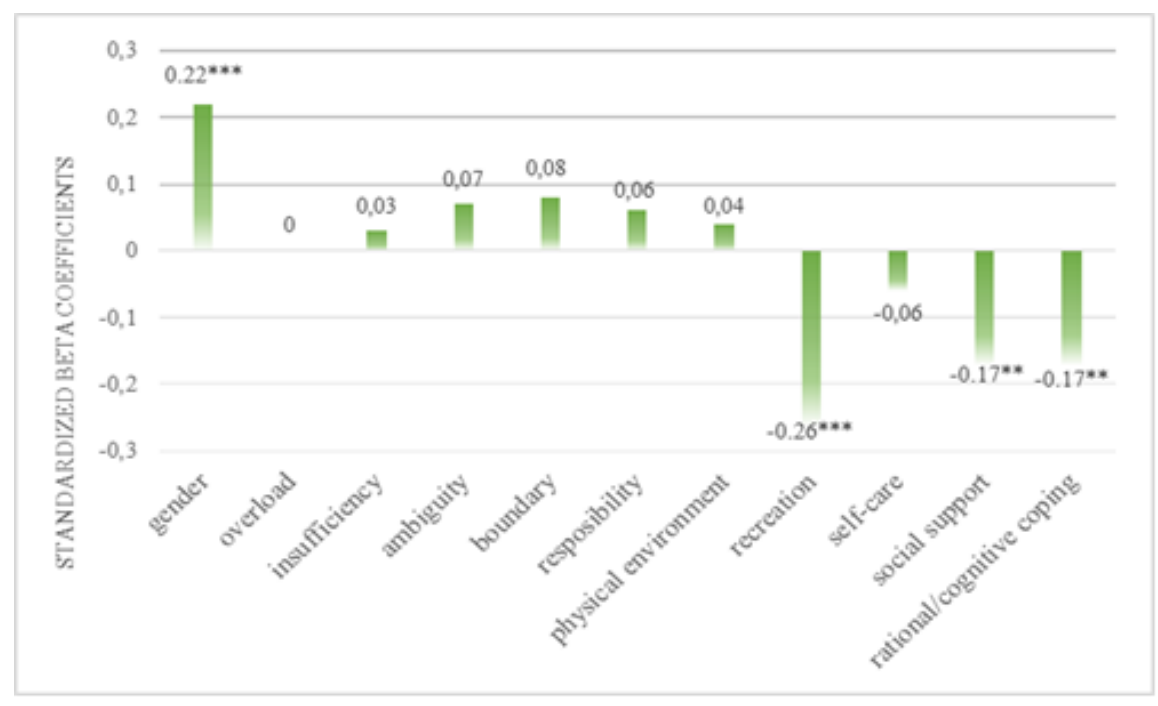

Notes: ${ }^{*} p \leq .05 ; * * p \leq .01 ; * * * p \leq .001$

Figure 3.

Multiple regression analysis: gender, occupational roles and personal resources on depression.

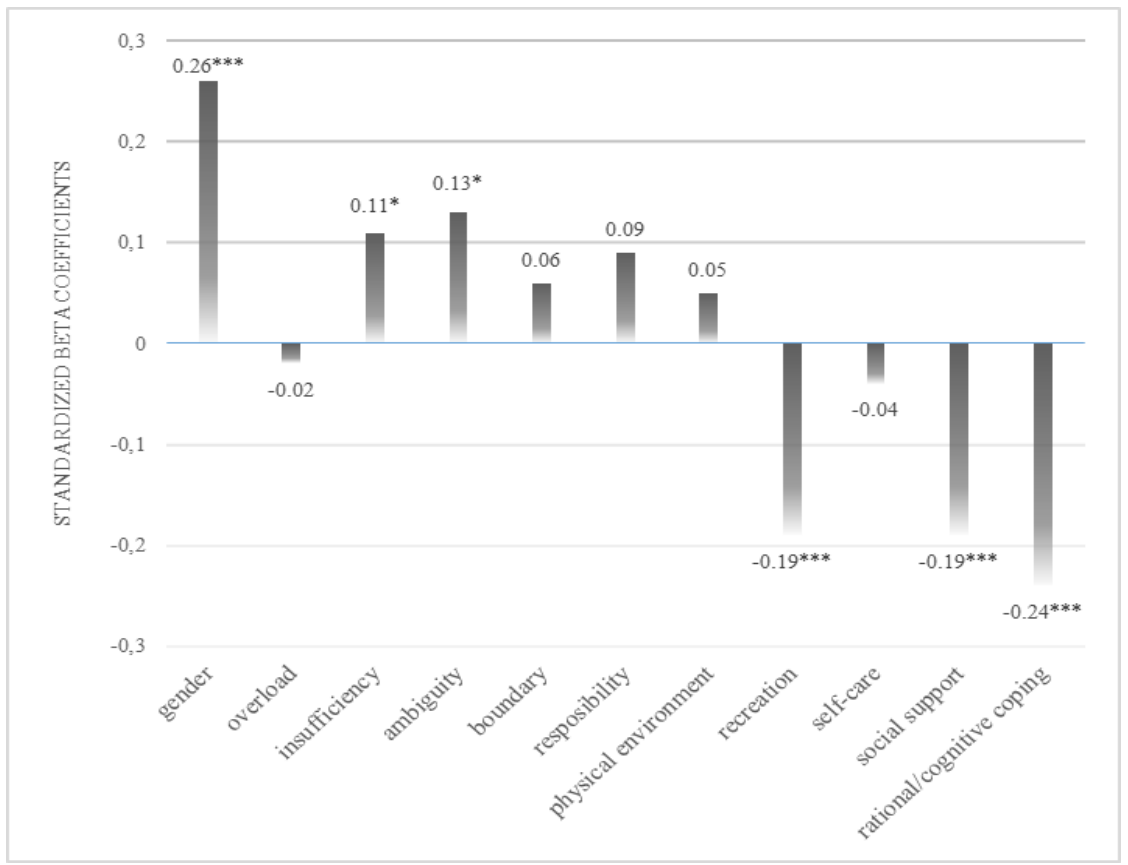

Notes: see Figure 2 


\section{DISCUSSION AND CONCLUSION}

In this study, associations among work related stress, coping resources and mental health were performed in a specific group of employees who perform, before the COVID-19 pandemic. There has been a lack of research on a mental health status of these employees in Slovakia till now.

The findings revealed that the female gender was a risk factor for anxiety and depression in the studied risk professions. For female employees in high-risk professions it is important to have stable personality traits including good self-efficacy and resilience, good time management skills, deal with less dangerous tasks at work, protect their overall health so they can take care of their family, and have adequate social support from their family. If they are vulnerable to anxiety or depression, it is necessary to address an occupational psychologist in their organization to find an appropriate individual solution how to stay healthy at work.

Furthermore, no work-related stress variables, apart from personal resources (except self-care), proved to be significant protective factors in developing of anxiety in employees at risk professions. Regarding depression, work-related stress variables, mainly role insufficiency and role ambiguity, were significant risk factors for its development. On the other hand, personal resources, except self-care, were showed as protective factors against depression. Higher levels of recreation, better social support, and good rational/cognitive coping strategies in the work of high-risk employees are important in diminishing the perceived anxiety and depression, and potentially in protecting against work-related stress.

The importance of this study for practice is a strong need to improve mental health at the workplace of high-risk professions. There is still a paucity of interventions that target psycho-social work factors in high-risk professions. Therefore, the design of effective interventions to promote employees' psychological well-being is very important. A significant number of medical conditions are strongly associated with depression, including chronic pain, heart disease, stroke, AIDS, chronic fatigue, and cancer. Adequate treatment of both the physical and mental disorders is essential for the employee's maximum recovery, regardless of whether the mental disorder is the primary disorder or secondary to medical problems. When an employee is suspected of having a mental health problem, someone in the management should consult a psychologist to evaluate the particular problem behavior and implement appropriate solutions (Pflanz \& Heidel, 2003; De Vente et al., 2008).

These findings are much more important in the present worldwide pandemic situation. They underline the need for aiming interventions for high-risk professions that can be on overall risk of development of stress-related disorders than in previous years. These interventions should focus on reducing insufficiency and ambiguity in their work, and more enhance recreation, social support and rational/cognitive coping strategies to avoid worsened psychological well-being of these employees (Patterson, Chung, \& Swan, 2014; Tsirigotis, Gruszczyński, \& Pęczkowski, 2015).

The limitation of this study included the demanding availability of responses from employees of high-risk professions, e. g. armed forces or doctors, who were too busy to participate in this study. Then, the low prevalence of anxiety and depressive symptoms in the studied sample has been related to normal levels of occupational stress and strong coping skills. This result could have been caused by distrust and fear that the research outcomes from an unknown person (researcher) would reach the leaders, or it could be caused by the fear of a job loss. This might be a potential bias that could have affected these findings. Furthermore, it can be assumed that those responders who were most affected by 
occupational stress avoided the research as they had no energy to deal with their exhaustion, either because of the above-mentioned concerns, or for other personal reasons. We also assume that those employees who attended work or did not perceive an increased occupational stress voluntarily participated in the study in contrast to those who refused to be included in the research. The present levels of anxiety and depression in the study group seem to confirm it. It is gratifying that the studied employees did not experience increased levels of anxiety or depression, which seems to be very important for their job achievement.

Since Slovakia does not have any specific regulations on work-related stress and occurrence of mental health problems due to stress, a future general legal framework should be created to protect employees from developing work-related stress (Žulová, 2019).

\section{REFERENCES}

Americká psychiatrická asociácia APA (2018). Príručka $k$ diagnostickým kritériám DSM-5. [Diagnostic and Statistical Manual of Mental Disorders DSM-5]. Bratislava: Vydavatel'stvo F.

Baumann, A., Muijen, M., \& Gaebel, W. (2010). Mental health and well-being at the workplace-protection and inclusion in challenging times. Copenhagen: The Regional Office for Europe of the World Health Organization.

Bennett, P. (2011). Abnormal and Clinical Psychology. Berkshire: Open University Press.

Cohen, S., \& Wills, T. A. (1985). Stress, Social Support, and the Buffering Hypothesis. Psychological Bulletin, 98(2), 310-357.

Chan, J. F., \& Andersen, J. P. (2020). Influence of organizational stress on reported depressive symptoms among police. Occupational Medicine, doi:10.1093/occmed/kqaa141.

De Vente, W., Kamphuis, J. H., Emmelkamp, P. M., \& Blonk, R. W. (2008). Individual and group cognitive-behavioral treatment for work-related stress complaints and sickness absence: a randomized controlled trial. Journal of Occupational Health Psychology, 13(3), 214-231.

Goldberg, P., David, S., Landre, M. F., Goldberg, M., Dassa, S., \& Fuhrer, R. (1996). Work conditions and mental health among prison staff in France. Scandinavian Journal of Work, Environment \& Health, 22, 45- 54.

Hofmann, S. G., Asnaani, A., Vonk, I. J., Sawyer, A.T., \& Fang, A. (2012). The efficacy of cognitive behavioral therapy: A review of meta-analyses. Cognitive Therapy and Research, 36(5), 427-440.

Krick, A., \& Felfe, J. (2020). Who Benefits from Mindfulness? The Moderating Role of Personality and Social Norms for the Effectiveness on Psychological and Physiological Outcomes among Police Officers. Journal of Occupational Health Psychology, 25(2), 99-112.

Lovaš, L., Raczová, B., Hricová, M., Mesárošová, M., \& Kováčová Holevová, B. (2014). Psychologické kontexty starostlivosti o seba. [Psychological contexts of self-care]. Košice: Univerzita Pavla Jozefa Šafárika.

Madsen, I. E., Nyberg, S. T., Hanson, L. M., Ferrie, J. E., Ahola, K., Alfredsson, L., Batty, G. D. ... IPD-Work Consortium (2017). Job strain as a risk factor for clinical depression: systematic review and meta-analysis with additional individual participant data. Psychological Medicine, 47(8), 1342-1356.

Maran, A. D., Varetto, A., Zedda, M., \& Ieraci, V. (2015). Occupational stress, anxiety and coping strategies in police officers. Occupational Medicine, 65(6), 466-473.

McCammon, S., Durham, T. W., Allison Jr., E. J., \& Williamson, J. E. (1988). Emergency Workers' Cognitive Appraisal and Coping with Traumatic Events. Journal of Traumatic Stress, 1(3), 353-372.

Müllner, J., Ruisel, I., Farkaš, G. (1980). Dotazník na meranie úzkosti a úzkostlivosti. [State-Trait Anxiety Inventory]. Bratislava: Psychodiagnostické a didaktické testy, n. p.

Národné centrum zdravotníckych informácií, NCZI. (2018). Psychiatrická starostlivost' v SR 2017. [Report of patients in inpatient psychiatric care in Slovakia in 2017]. Bratislava: NCZI. 
Osipow, S. H. (2010). Inventórium zamestnaneckého stresu OSI-R. [Occupational Stress Inventory-Revised OSI-R]. Bratislava: Psychodiagnostika a. s.

Patterson, G. T., Chung, I. W., \& Swan, P. W. (2012). The effects of stress management interventions among police officers and recruits. Campbell Systematic Reviews, 8(1), 1-54. doi: $10.4073 /$ csr.2012.7.

Patterson, G. T., Chung, I. W., \& Swan, P. W. (2014). Stress management interventions for police officers and recruits: a meta-analysis. Journal of Experimental Criminology, 10(4), 487-513.

Pflanz, S., Heidel, S.H. (2003). Psychiatric causes of workplace problems. In: J. P. Kahn, A. M. Langlieb (Eds.), Mental Health and Productivity in the Workplace (pp. 276-296). San Francisco, CA: Jossey-Bass.

Sarason, I. G., Johnson, J. H., Berberich, J. P., \& Siegel, J. M. (1979). Helping Police Officers to Cope with Stress: A Cognitive-Behavioral Approach. American Journal of Community Psychology, 7(6), 593-603.

Schneider, A., \& Weigl, M. (2018). Associations between psychosocial work factors and provider mental well-being in emergency departments: a systematic review. PLoS ONE 13(6): e0197375. doi: 10.1371/journal.pone.0197375.

Schwartz, R., Haverfield, M., Brown-Johnson, C., Maitra, A., Tierney, A., Bharadwaj, S., Jonathan, S., Azimpour, F., Thadaney, S., Verghese, A., \& Zulman, D. (2019). Transdisciplinary Strategies for Physician Wellness: Qualitative Insights from Diverse Fields. Journal of General Internal Medicine 34(7), 1251-1257.

Sherwood, L., Hegarty, S., Vallières, F., Hyland, P., Murphy, J., Fitzgerald, G., \& Reid, T. (2019) Identifying the Key Risk Factors for Adverse Psychological Outcomes Among Police Officers: A Systematic Literature Review. Journal of Traumatic Stress, 32(5), 688-700. doi: $10.1002 /$ jts. 22431

Stein, D. J., \& Hollander, E. (2003). Anxiety and stress. In: J. P. Kahn, \& A. M. Langlieb (Eds.), Mental Health and Productivity in the Workplace (pp. 407-432). San Francisco, CA: Jossey-Bass.

Sun, J., Sun, R., Jiang, Y., Chen, X., Li, Z., Ma, Z., Wei, J., He, Ch., \& Zhang L. (2020). The relationship between psychological health and social support: Evidence from physicians in China. PLoS ONE, 15(1), e0228152. Retrieved from https://doi.org/10.1371/journal.pone.0228152.

Tsirigotis, K., Gruszczyński, W., \& Pęczkowski, S. (2015). Anxiety and styles of coping with occupational stress resulting from work with 'dangerous' prisoners in prison service officers. Acta Neuropsychiatrica, 27(5), 297-306.

Zung, W. W. (1991). Hodnotenie depresie. [Self-Rating Depression Scale]. Bratislava: Léčiva.

Žulová, J. (2019). Rešerš právnych predpisov na zaistenie BOZP. [The search of legal regulations for ensuring occupational health and safety]. Košice: Univerzita Pavla Jozefa Šafárika.

\section{ACKNOWLEDGEMENTS}

This study was part of the APVV-16-0002 project Mental Health in the Workplace and Employee Health Assessment.

\section{AUTHORS' INFORMATION}

Full name: Martina Chylová, PhDr., PhD.

Institutional affiliation: 1st Department of Psychiatry, Faculty of Medicine, P. J. Šafárik University in Košice, Slovakia

Institutional address: Tr. SNP 1, Košice 040 11, Slovakia

Short biographical sketch: Martina Chylová is a clinical psychologist and assistant professor. She completed her doctoral program in Health Sciences (University Medical Center Groningen, the 
Netherlands) in 2009. Her teaching and practical activities associate with health psychology, clinical psychology, and psychopatology in adulthood. She conducts investigations in the research projects focusing on employees' mental health and its assessement, improving mental health status in patients with psychiatric illnesses. She also helps students with psychological problems as a counselor at University counselling center UNIPOC in Košice. She is a member of the Slovak Chamber of Psychologists.

Full name: Jana Nezkusilová, Mgr., PhD.

Institutional affiliation: Department of Psychology, Faculty of Arts, P. J. Šafárik University in Košice, Slovakia

Institutional address: Moyzesova 9, Košice 041 80, Slovakia

Short biographical sketch: Jana Nezkusilová works as a lecturer and researcher at the Department of Psychology. Her main field of research is stress, health-related behavior, and high-risk professions. She is also part of an international team at the project COVIDiSTRESS global survey, studying the effect of COVID-19 pandemic on mental health and the behavioral response to the pandemic situation. At the university, she teaches psycho-diagnostics, developmental disorders, and qualitative research. She works also as a child counselor.

Full name: Monika Minčičová Seilerová, JUDr., PhD.

Institutional affiliation: Department of Labour Law and Social Security Law, Faculty of Law, P. J. Šafárik University in Košice, Slovakia

Institutional address: Kováčska 26, Košice 040 75, Slovakia

Short biographical sketch: Monika Seilerová works as a researcher at the Department of Labour Law and Social Security Law. Her research concerns several areas. She currently focuses mainly on the possibilities of improving the legal framework for employees' health care and wellbeing, including the legal regulation of employees' health assessment. In publications, she also deals with issues of the interconnection of civil law with labour law, with issues of employment services or consequences of digitisation on labour law relations. She partially participates as a teacher, lecturing in the field of labour law. She is also active in the organisation of scientific conferences, student symposiums and other popularisation activities. 